\title{
Opinions of French patients with schizophrenia regarding injectable medication
}

\author{
This article was published in the following Dove Press journal: \\ Patient Preference and Adherence \\ 18 March 201 I \\ Number of times this article has been viewed
}

\author{
François Caroli ${ }^{1}$ \\ Philippe Raymondet ${ }^{2}$ \\ Isabelle Izard ${ }^{3}$ \\ Joel Plas ${ }^{4}$ \\ Bérengère Gall ${ }^{5}$ \\ Antonio Delgado 6 \\ 'Psychiatry Department, Centre \\ Hospitalier Sainte-Anne, Paris, \\ France; ${ }^{2}$ Psychiatry Department, CMP \\ Chalucet, Toulon, France; ${ }^{3}$ Psychiatry \\ Department, CMP Jean Wier, Suresnes, \\ France; ${ }^{4}$ Psychiatry Department, $\mathrm{CH}$ \\ Jean Charcot, Vélizy, France; ${ }^{5}$ Opinion \\ and Health Department, BVA Group, \\ Boulogne-Billancourt, France; \\ ${ }^{6}$ Neurosciences Department, Janssen \\ Cilag France, Issy-les-Moulineaux, \\ France
}

Background: Use of patient-reported outcomes to assess the care of individuals with schizophrenia is increasing. We describe a survey (questionnaire) that evaluates patient opinions on long-acting injectable antipsychotic medication.

Methods: Psychiatrists throughout France selected consenting patients with schizophrenia who had received at least three months' treatment with a long-acting injectable antipsychotic (either typical or atypical) as outpatients to be interviewed by professional interviewers.

Results: A total of 206 patients were interviewed at 19 sites. Ninety-five percent of the patients had been treated with more than one form of dosage; for these individuals, injections were the favored dosage form, being preferred by $47 \%$ (compared with $35 \%, 7 \%$, and $1 \%$ expressing a preference for oral tablets, drinkable solutions, and orally disintegrating tablets, respectively, whilst $10 \%$ of patients did not express a preference). Over two-thirds of the interviewees (67\%) said they felt better having received an injectable treatment than they felt before, and over half the patients $(51 \%)$ considered injectable therapy to be more effective than other medication. In addition, the majority of the sample (70\%) felt better supported in their illness by virtue of regular contact with the doctor or nurse who administered their injection. Patients also reported that injectable treatment could impact positively on their plans and aspirations, with the most frequent consideration for the future relating to finding a job (49\% of the sample).

Conclusion: In this survey, patients with schizophrenia had favorable opinions on injectable medication. Ultimately, positive experiences associated with the treatment of schizophrenia in patients receiving long-acting injectable medication may influence the prescription of such therapy by health care providers.

Keywords: schizophrenia, patient opinion, antipsychotic agents, depot preparations, dosage forms, injections

\section{Introduction}

When patients receive treatment for schizophrenia, long-acting injectable forms of typical antipsychotic medication are an option that has been used to ensure compliance with maintenance therapy. ${ }^{1}$ However, treatment with typical medication often produces side effects, including weight gain, sedation, hypotension, seizures, acute extrapyramidal symptoms (eg, parkinsonism, akathisia, and dystonia), and chronic motor problems (eg, tardive dyskinesia, chronic akathisia, and tardive dystonia). ${ }^{2,3}$ Consequently, although injecting such drugs (which are also available in tablet or liquid form) may be regarded as convenient from the perspective of the health care provider, patients may require coercing to accept them. Indeed, coercion has been highlighted as a conceptual issue in a consideration of the ethical use of medication in the treatment of severe and persistent
Correspondence: François Caroli Psychiatry Department, Centre Hospitalier Sainte-Anne, I rue Cabanis, 75674 Paris Cedex, France

Tel +33 I45658309

Fax +33 I45658740

Email f.caroli@ch-sainte-anne.fr 
mental illness, ${ }^{4}$ and health care providers may have negative attitudes towards injectable antipsychotic medication. ${ }^{5,6}$

New-generation, atypical antipsychotic therapies have become available. Results from long-term clinical studies have suggested that atypical medication may have advantages over orally administered typical drugs, with patients having fewer relapses, more effective symptom control, and a lower incidence of movement disorders, although weight gain may be an issue. ${ }^{7}$ The clinical advantage of oral atypical antipsychotic agents may be limited by compliance, and longacting preparations of these drugs can afford the opportunity to achieve consistent and sustained drug coverage. ${ }^{7}$ Thus, attention should be given to injectable depot antipsychotic therapy, which, with the advent of atypical preparations, may help to address compliance issues.

Given the potential benefits of the new generation of antipsychotic drugs, it is valuable to determine patients' current opinions towards the prescription of long-acting injectable medication, and the nature of the relationships between patients and health care providers. Patient-reported outcomes are being used increasingly to assess the care of individuals with schizophrenia, ${ }^{8}$ and we describe a survey designed to evaluate patient opinion on long-acting intramuscular antipsychotic medication. The survey, which involved patients regardless of whether they were receiving typical or atypical drugs, also considered broader issues, ie, patients' perception of their illness, information received in relation to schizophrenia, and other forms of prescribed medication. Ultimately, adding to this body of knowledge may influence health care providers when considering the prescription of long-acting injectable antipsychotic medication for patients with schizophrenia.

\section{Methods}

\section{Survey}

The content, wording, and order of the questions in the survey were developed by a scientific steering committee (details of which are given in the Acknowledgments). The questions were subsequently approved by the Union Nationale des Amis et Familles des Malades Mentaux (the National Union of Friends and Families of Mental Health Patients) and the Fédération Nationale des Associations d'Usagers en Psychiatrie (National Federation of Associations of Users in Psychiatry). After initially piloting the survey in 14 patients, a slightly amended version was validated by BVA, a market and opinion research agency (Boulogne-Billancourt, France), which specializes in opinion and health care, and respecting appropriate ethical standards.
The questions covered three areas, ie, patients' perception of their illness and the information they had received in relation to schizophrenia, the various forms of treatment the patients had received, and specific issues relating to injectable treatment (Table 1). Some of the questions required answers to be selected from multiple-choice options, whereas others were open-ended.

\section{Sampling}

The survey was conducted in outpatient clinics and day care centers throughout France, with potential sites and physicians being identified by Janssen Cilag, France. Psychiatrists who agreed to participate selected appropriate patients with schizophrenia who might wish to be included in the survey. To be eligible to participate, patients should have received at least three months' treatment with a long-acting injectable antipsychotic (either typical or atypical) on an outpatient basis (attending hospitals or day care centers), with the psychiatrist considering their condition to have remained stable during this time. All patients were required to provide informed consent. Patients whose condition was not judged to be sufficiently stable were excluded, as were individuals who did not provide consent.

\section{Interviews}

Interviews were conducted by 11 professional interviewers from the BVA agency who were experienced in the field of behavioral health. The interviews took place after the patients' consent had been obtained, and in accordance with the availability of the patients and their professional health care providers. The majority of interviews were held during an outpatient consultation or in a day care center. The interviews generally lasted around 15 minutes, with patients being asked each question as appropriate (ie, some items were filtered according to patients' responses). Interviewers met patients face-to-face, and health care providers were not present during the interview. Anonymized written records of the interviews were produced.

\section{Data analysis}

No formal sample size calculation was performed. However, a sample of 200 patients was targeted, from which it was estimated that approximately 20 psychiatrists could each enroll around 10 patients. Data were analyzed for the entire sample of patients who participated in the survey. Answers to multiple-choice questions were expressed in terms of the percentage of patients giving a particular response. For open-ended questions, the most frequently cited responses were categorized and quantified accordingly. 
Table I Questions included in the survey

Patients' perception of their illness and information received in relation to schizophrenia

Do you feel ill?

Do you know the name of the illness you have? If so, what is it? (Spontaneous answer)

Who informed you that you were ill? (Spontaneous answer)

Since you became ill, who has most regularly provided you with information about your illness? (Spontaneous answer)

When someone talked to you about your illness for the first time, did he or she give you any information or an explanation about treatment for the illness?

Since you were informed you were ill:

Have the medical staff been listening to you?

Have the medical staff answered all your questions?

Has the information you have received been clear?

Has the information you have received been sufficient?

Forms of treatment administered to the patients

Since you became ill, which of the following treatments have you used?

Injections

Tablets taken with water

Drinkable solution (drops)

Tablets that melt in the mouth

For patients who had received at least two forms of medication:

Of those treatments you have used, which do you prefer?

For patients who preferred injections:

Please give the reason for your preference (Spontaneous answer)

For patients who preferred tablets:

Please give the reason for your preference (Spontaneous answer)

Injectable treatment

Do you know why this injectable treatment was prescribed for you? (Spontaneous answer)

Did the doctor who prescribed this injectable treatment for you talk about the following?

The place where you can inject yourself

The frequency of the injections

The advantages of this injectable treatment over other treatments

Possible undesirable effects of this treatment

How do you feel today after having received an injectable treatment?

For patients who felt better than before:

What for you are the main advantages of your injectable treatment? (Spontaneous answer)

I am going to quote you various opinions. Please tell me if they correspond quite closely or quite poorly to your feelings about your treatment:

Injectable treatment is more effective against my symptoms and my illness than tablets (or a drinkable solution).

Injectable treatment has fewer undesirable effects than tablets (or a drinkable solution).

Either a nurse or a doctor gives me my injection, so I feel better supported in my illness.

Have you ever skipped an injection on purpose without having talked about it beforehand with a doctor?

Does the injectable treatment that you are now receiving allow you to envision your plans and aspirations more optimistically?

What are your current plans and aspirations? (Spontaneous answer)

Notes: The questions listed above are generally shown according to their presentation in this article, which is not necessarily indicative of the order in which they were asked in the survey. Whereas some of the questions required answers to be selected from multiple-choice options, others were open-ended, with spontaneous answers being obtained as shown above.

Because patients were not asked to provide any details as to the specific treatments they were receiving (they were only questioned as to the way in which the medication was administered, eg, injectable, oral tablets), the results do not differentiate between typical and atypical drugs.

\section{Results}

\section{Patients}

A total of 206 patients from 19 sites throughout France were interviewed between May 2007 and July 2007. These patients had been under the care of a psychiatrist for a mean ( \pm standard deviation) of $12( \pm 10)$ years. Baseline characteristics of the interviewees are shown in Table 2 The majority of patients interviewed were male and not engaged in any occupational, educational, or voluntary activity.

\section{Patients' perception of illness and information received on schizophrenia}

Thirty-nine percent of the patients interviewed did not feel that they were ill, and a minority (28\%) of the sample knew they had a diagnosis of schizophrenia. Indeed, the name of their disease was unknown to $37 \%$ of the patients surveyed, whilst $35 \%$ of the sample believed their illness to 
Table 2 Baseline characteristics of the patients surveyed $(n=206)$

\begin{tabular}{ll}
\hline Characteristic & Percentage of patients \\
\hline Gender & 65 \\
Male & 35 \\
Female & \\
Age (years) & 29 \\
$<35$ & 48 \\
$35-49$ & 23 \\
$\geq 50$ & \\
Living arrangement & 43 \\
Alone & 38 \\
With family & 10 \\
With partner & 8 \\
Social institution & 13 \\
Engagement in occupational, educational, & \\
or voluntary activity & $\left.5\right|^{\text {a }}$ \\
Engagement in leisure activity &
\end{tabular}

Note: af whom $16 \%$ belonged to a club or self-help group.

be a condition other than schizophrenia (mainly depression, psychological problems, or bipolar disorder).

The majority of patients had been informed of their illness by a psychiatrist (59\%) or general practitioner (23\%), and most (91\%) of the sample had also received information about their condition; this information was generally provided by a psychiatrist $(85 \%)$ or nurse $(29 \%)$, and only $1 \%$ of patients reported self-instigated searches/ use of the Internet. Thirty-two percent of patients claimed to have received no information about the condition or its treatment at the time of diagnosis. When information was given to patients, this was generally received positively, with the majority of the sample considering that medical staff had listened to them and answered all their questions ( $89 \%$ and $81 \%$ respondents, respectively). However, there remained a requirement for patients to be given information that was more complete and more clear.

\section{Forms of treatment administered to patients}

Patients had received a mean of three different forms of treatment. All had received an injectable drug, because this was a requirement for inclusion in the survey, and $95 \%$ of the sample had been treated with more than one form of medication. Oral tablets (to be taken with water), drinkable solutions, and orally disintegrating tablets had also been prescribed (for $94 \%, 52 \%$, and $28 \%$ of patients, respectively). In patients who had received therapy with at least two forms of medication, injections were the favored dosage form, being preferred by $47 \%$ of the sample (Table 3 ). The most frequently given reasons for patients preferring injections were that the doses were spread out over time ( $41 \%$ of patients in whom this
Table 3 Preferred treatment as described by patients who had used at least two forms $(n=196)$

\begin{tabular}{ll}
\hline Description & Percentage of patients \\
\hline Injections & 47 \\
Tablets taken with water & 35 \\
Drinkable solutions & 7 \\
Orally disintegrating tablets & 1 \\
Patients did not know & 10 \\
\hline
\end{tabular}

was the favored treatment modality), and there was no risk of forgetting a dose (39\%). In those patients who preferred tablets to be taken with water, the most frequently stated basis for this was a dislike of injections (32\%). Responses from the survey suggested that patients often had a favorable opinion of injectable medication, and this form of treatment was subsequently considered in more detail.

\section{Injectable treatment}

The most common reasons cited by patients as the grounds for which their injectable treatment had been prescribed were the constraints, or lack of effectiveness, of previous therapy ( $40 \%$ and $39 \%$, respectively). When the injections were instigated, the majority of the information about the treatment given to the patients by physicians was concerned with practical details of the injection procedure (injection site [described to $97 \%$ of the sample] and injection frequency [described to $93 \%$ of the sample]). Less information was described in relation to the advantages and possible side effects of the injectable treatment, with $37 \%$ of patients unable to recall being given any details of these two aspects of the therapy. This group of patients comprised mainly those who were unaware of the reason for their being prescribed the injectable treatment (66\%) or the reason for their being followed-up (47\%), and individuals over 50 years of age $(51 \%)$.

Over two-thirds of the sample (67\%) said they felt better having received an injectable treatment than they did before (Table 4 ), and over half the patients $(51 \%)$ considered the injectable treatment to be more effective than other medication. Patients who felt better than before reported the following main advantages of injectable treatment: feeling

Table 4 Patients' feelings after having received an injectable treatment $(n=206)$

\begin{tabular}{ll}
\hline Description & Percentage of patients \\
\hline Better than before & 67 \\
Neither better nor worse & 23 \\
Not as well as before & 8 \\
Patients did not know & 2 \\
\hline
\end{tabular}


less anxious, calmer (67\%); feeling less depressed or having a better mood (30\%); feeling more resilient/energetic (24\%); having fewer hallucinations (15\%); and being more sociable/ having friends (11\%). In addition to such benefits, the majority of the sample $(70 \%)$ felt better supported in their illness by virtue of regular contact with the doctor or nurse who administered their injection. Indeed, $88 \%$ of patients had never deliberately missed an injection without having discussed this beforehand with their doctor.

Injectable treatment may also impact positively on patients' plans and aspirations; $47 \%$ of the sample reported that the therapy allowed them to view their plans and aspirations more optimistically. The most frequent considerations for the future related to finding a job ( $49 \%$ of the sample) and concerns for social and family lives $(22 \%)$. Other aspirations related to leisure activity (19\%), greater autonomy (17\%), and cure (10\%).

No differences with regard to undesirable side effects were apparent between injectable medication and treatments administered via an oral route. When presented with the statement "Injectable medication has fewer undesirable effects than tablets (or a drinkable solution)", 30\% of respondents reported this to correspond closely with their feelings, 30\% reported a poor correspondence, and $40 \%$ did not know.

\section{Discussion}

Injections were the form of antipsychotic medication preferred by most of the patients in our survey. However, this study had its limitations, in that all the interviewees were receiving long-acting injectable drugs, and the results were obtained from a relatively small sample of patients, recruited over a short period of time. This may raise a question as to the degree to which our findings can be extended to other patients with schizophrenia. However, in this context, it is appropriate to note that, as described below, patients reporting a favorable perception towards injectable antipsychotic medication is in line with other published findings.

Although few data have described the subjective experiences of people who receive depot injections in the community, ${ }^{9}$ the data that are available, although of variable quality, generally show patients to be positive in their perception of injectable antipsychotic medication. Two previously published reviews ${ }^{10,11}$ identified 12 studies describing specific attitudinal or preferential data. ${ }^{12-23}$ Ten of these studies, all of which were cross-sectional surveys, conveyed positive opinions of depot medication. ${ }^{12,14-18,20-23}$ Six of the 12 studies identified in the reviews directly compared patient preferences for depot and oral treatments. ${ }^{13,14,16,17,20,23}$ In five of these six studies, depot medication was preferred by more patients. ${ }^{14,16,17,20,23}$

Hovens et $\mathrm{al}^{24}$ have subsequently reported that patients with schizophrenia prefer long-acting injections, describing the results of semistructured interviews performed with 92 outpatients who were receiving antipsychotic medication. The patients in this sample considered long-acting injections to offer the most advantages and the fewest disadvantages of all methods of administration of antipsychotic drugs, regardless of the treatment they were receiving (conventional oral medication, atypical oral medication, conventional longacting injections, or atypical long-acting injections) when they expressed this opinion.

In a recent survey of 300 patients shortly before discharge from a psychiatric hospital, Heres et $\mathrm{al}^{25}$ found the preference for depots as favorable antipsychotic medication to depend on patients' experience with the formulation, and a considerable number of patients were willing to accept a depot drug for long-term treatment.

However, despite patients' generally favorable perception of injectable antipsychotic medication, as described in the results earlier, practicing psychiatrists and nurses may be surprised that patients prefer injections. Health care providers' perception of patients' overall experience of such therapy may be influenced by experience of administering injections, because the injection procedure itself may not be particularly agreeable for the health care provider or for the patient. In addition, health care providers may consider injections as a means of maintaining control over drug administration. Indeed, previous reports have shown that psychiatrists and nurses may have negative attitudes towards long-acting injections. ${ }^{5,6}$ When depot medication is not prescribed for patients, the reasons given for not prescribing this treatment may not be supported by available evidence. ${ }^{26}$

In our survey, $67 \%$ of patients claimed to feel better having received an injected drug. This might be expected, given the benefits of effective long-term maintenance therapy in schizophrenia, the relative convenience of the treatment (preclusion of the requirement to take medication daily), and the support provided through regular contact with health care providers when patients attend appointments to receive injections. Indeed, $70 \%$ of our sample said that they felt better supported in their illness; in addition to assistance, health care providers can offer reassurance, helping patients in their decision to receive medication. The time that nurses spend with patients at clinics when injections are administered can enable relationships to develop that extend beyond merely the provision of a biological intervention 
in schizophrenia, providing a forum enabling patients to discuss both clinical and psychosocial issues relating to their condition. ${ }^{9}$ This may contrast with the situation for patients with schizophrenia prescribed oral drugs, who have to make decisions to comply with treatment on a daily basis, ie, decisions that may be made alone and can be adversely influenced if patients do not believe themselves to be ill.

Our results raise several other interesting points in relation to patients' perception of schizophrenia and the manner in which they are treated. Whilst a minority (28\%) of the sample were aware that they had schizophrenia, this does not necessarily indicate that the patients did not understand the symptoms and problems associated with the disease. Indeed, previous data have confirmed that patients can understand the nature of their illness. ${ }^{27}$ However, it is possible that, in some instances, a diagnosis of schizophrenia may not have been specified to avoid labeling a patient. Rather than reduce discussion to a dialog focused exclusively on the diagnosis, the health care providers involved may have attached more importance to providing support, and helping patients to recognize and deal with problems they are liable to experience as a consequence of having the condition.

That information about schizophrenia was generally provided to patients by a psychiatrist ( $85 \%$ of the sample) or nurse ( $29 \%$ of the sample) demonstrates links in the team providing health care, and such links can help to facilitate the provision of effective treatment and patient support. In relation to this, the importance of postdiagnostic education should be emphasized, because the knowledge gained will help patients to understand better the nature of their condition and the means of treating it. Well-informed patients are likely to be more receptive to treatment and to acknowledge its benefits, and transparency of information given to patients by health care providers is likely to produce greater acceptability of therapy.

Patients with schizophrenia may wish to be involved in decisions about their treatment. ${ }^{28}$ Rather than being coerced into receiving injections, patients should be actively involved in their own care, and the provision of comprehensive information may help patients to decide to attend clinics where they can be given appropriate treatment. Encouragingly, most patients in the sample found medical staff responsive and ready to answer questions, reporting all their questions to be answered. However, the information provided to patients was not always regarded as sufficiently complete or clear enough. Whilst the survey found that patients tended to be well informed about practical details relating to the injectable medication, interviewees claimed to have received less information concerning the advantages and possible disadvantages of such treatment. This might, in part, reflect the attitudes of psychiatrists, who can find it more difficult to promote injections if they regard them as having disadvantages for patients, or being an obligation. The value of updating psychiatrists' knowledge of depot medication, so as to promote a more positive attitude, has been highlighted in the literature. ${ }^{5,6}$

This survey showed that patients receiving injectable treatment reported subsequent positive effects on their aspirations, with treated patients making plans relating to assimilation into society, such as finding a job and integrating into social and family life. Patients may realize that although they cannot be cured, they can still have ambitions for the future.

In conclusion, injectable medication was the dosage form preferred by most patients in this survey. This preference is in line with previously published results showing positive patient attitudes towards injectable treatment, but may surprise practicing psychiatrists and nurses. Patients in this survey claimed to feel better having received an injected drug, and said that they felt better supported in their illness. They also reported that injectable medication could allow them to view their plans and aspirations more optimistically. Patients rated health care providers positively, generally finding them willing to provide information, support, and reassurance. Ultimately, more positive experiences associated with the treatment of schizophrenia in patients receiving longacting injectable medication may influence the prescription of such therapy by health care providers.

\section{Acknowledgments}

The scientific steering committee comprised FC, PR, and II. Janssen Cilag, France express their sincere thanks to the following physicians and scientists who participated in this survey: V Adnet Markovitch, Mont-Saint-Martin; C Amoyal, Toulouse; B Beaufils, Issy les Moulineaux; R De Beaurepaire, Villejuif; M Blanc, Jury les Metz; E Giraud Baro, Grenoble; I Giraudon, Paris; R Gourevitch, Paris; MS Kasmi, Eaubonne; M Hodgkinson, Marseille; M Maurel, Marseille; G Masse, Paris; P Martin, Paris; J Palazzolo, Nice; J Plas, Vélizy; J Pon, Montberron; P Raymondet, Toulon; G Saba, Créteil; S Said, Paris; S Zahzouh, Antony.

\section{Disclosure}

This study was funded by Janssen Cilag, France. AD is an employee of Janssen Cilag, France. The other authors have no conflicts of interest to report in this work. 


\section{References}

1. Altamura AC, Sassella F, Santini A, et al. Intramuscular preparations of antipsychotics: uses and relevance in clinical practice. Drugs. 2003; 63:493-512.

2. Barnes TR, McPhillips MA. Novel antipsychotics, extrapyramidal side effects and tardive dyskinesia. Int Clin Psychopharmacol. 1998;13 Suppl 3:S49-S57.

3. Lader M. Some adverse effects of antipsychotics: prevention and treatment. J Clin Psychiatry. 1999;60 Suppl 12:18-21.

4. Roberts LW, Geppert CM. Ethical use of long-acting medications in the treatment of severe and persistent mental illnesses. Compr Psychiatry. 2004;45:161-167.

5. Patel MX, de Zoysa N, Baker D, David AS. Antipsychotic depot medication and attitudes of community psychiatric nurses. J Psychiatr Ment Health Nurs. 2005;12:237-244.

6. Patel MX, Nikolaou V, David AS. Psychiatrists' attitudes to maintenance medication for patients with schizophrenia. Psychol Med. 2003; 33:83-89.

7. Turner MS, Stewart DW. Review of the evidence for the long-term efficacy of atypical antipsychotic agents in the treatment of patients with schizophrenia and related psychoses. J Psychopharmacol. 2006; 20(Suppl 6):20-37.

8. McCabe R, Saidi M, Priebe S. Patient-reported outcomes in schizophrenia. Br J Psychiatry Suppl. 2007;50:S21-S28.

9. Phillips L, McCann E. The subjective experiences of people who regularly receive depot neuroleptic medication in the community. J Psychiatr Ment Health Nurs. 2007;14:578-586.

10. David AS, Adams C. Depot antipsychotic medication in the treatment of patients with schizophrenia: (1) meta-review; (2) patient and nurse attitudes. Health Technol Assess. 2001;5:1-61.

11. Walburn J, Gray R, Gournay K, Quraishi S, David AS. Systematic review of patient and nurse attitudes to depot antipsychotic medication. Br J Psychiatry. 2001;179:300-307.

12. Anderson D, Leadbetter A, Williams B. In defence of the depot clinic. The consumers' opinion. Psychiatr Bull. 1989;13:177-179.

13. Desai N. Switching from depot antipsychotics to risperidone: results of a study of chronic schizophrenia. Adv Ther. 1999;16:78-88.

14. Eastwood N, Pugh R. Long-term in depot clinics and patients' rights: an issue for assertive outreach. Psychiatr Bull. 1997;21:273-275.
15. Goldbeck R, Tomlinson S, Bouch J. Patients' knowledge and views of their depot neuroleptic medication. Psychiatr Bull. 1999;23:467-470.

16. Hoencamp E, Knegtering H, Kooy US, van Der Molen AEGM. Patient requests and attitude towards neuroleptics. Nord J Psychiatry. 1995; 49 Suppl 35:47-55.

17. Jacobsson L, Odling H. Psychological aspects of depot treatment of schizophrenic syndromes. Lakartidningen. 1980;77:3522-3526. Swedish.

18. Larsen EB, Gerlach J. Subjective experience of treatment, sideeffects, mental state and quality of life in chronic schizophrenic outpatients treated with depot neuroleptics. Acta Psychiatr Scand. 1996; 93:381-388

19. Pan PC, Tantam D. Clinical characteristics, health beliefs and compliance with maintenance treatment: a comparison between regular and irregular attenders at a depot clinic. Acta Psychiatr Scand. 1989;79: 564-570.

20. Pereira S, Pinto R. A survey of the attitudes of chronic psychiatric patients living in the community toward their medication. Acta Psychiatr Scand. 1997;95:464-468.

21. Singh V, Hughes G, Goh E. Depot clinic: consumers' viewpoint. Psychiatr Bull. 1995;19:728-730.

22. Warren B. Developing practice through clinical audit. Journal of Clinical Effectiveness. 1998;3:151-154.

23. Wistedt B. How does the psychiatric patient feel about depot treatment: compulsion or help? Nord J Psychiatry. 1995;49 Suppl 35:41-46.

24. Hovens JE, Roman B, van Dinther R. Patients with schizophrenia prefer long-acting injections. Schizophr Res. 2006;81 Suppl:S84.

25. Heres S, Schmitz FS, Leucht S, Pajonk FG. The attitude of patients towards antipsychotic depot treatment. Int Clin Psychopharmacol. 2007; 22:275-282.

26. Heres S, Hamann J, Kissling W, Leucht S. Attitudes of psychiatrists toward antipsychotic depot medication. J Clin Psychiatry. 2006;67: 1948-1953.

27. Lachaux B. Study of patients with schizophrenic pathologies. Journal de Psychiatrie. 2006;19:1-8. French.

28. Hamann J, Cohen R, Leucht S, Busch R, Kissling W. Do patients with schizophrenia wish to be involved in decisions about their medical treatment? Am J Psychiatry. 2005;162:2382-2384.
Patient Preference and Adherence

\section{Publish your work in this journal}

Patient Preference and Adherence is an international, peer-reviewed, open access journal focusing on the growing importance of patient preference and adherence throughout the therapeutic continuum. Patient satisfaction, acceptability, quality of life, compliance, persistence and their role in developing new therapeutic modalities and compounds to

\section{Dovepress}

optimize clinical outcomes for existing disease states are major areas of interest. This journal has been accepted for indexing on PubMed Central. The manuscript management system is completely online and includes a very quick and fair peer-review system. Visit http://www.dovepress.com/ testimonials.php to read real quotes from published authors. 